\title{
Reciprocal Fit Concept in Mission Statement Research
}

\author{
Seong-Yuen Toh \\ Department of Management, Sunway University \\ 5, Jalan Universiti, Bandar Sunway, \\ 47500 Petaling Jaya \\ Selangor, Malaysia \\ seongyuent@sunway.edu.my \\ Sadia Ahmed Mughal \\ Universiti Kuala Lumpur, \\ Universiti Kuala Lumpur Business School, \\ Kuala Lumpur, Wilayah Persekutuan \\ Malaysia \\ sadiaahmed03@hotmail.com
}

\author{
Jason Cheok \\ Department of Management, Sunway University \\ 5, Jalan Universiti, Bandar Sunway, \\ 47500 Petaling Jaya \\ Selangor, Malaysia \\ cheokbc@sunway.edu.my
}

\begin{abstract}
There is a stalemate in mission-performance research. While past studies focus on strategic alignment, recent studies attempt to move the mission-performance research forward using the reciprocal fit concept. This concept provides explanatory power in predicting performance of the firm. However, there is a lack of research into the reciprocal fit concept. The concept needs further clarification. This study aims to elucidate the concept of reciprocal fit by: (1) investigating the theoretical underpinning of the fit concepts; (2) identifying the conditions of reciprocal fit; and (3) find empirical evidence supporting this reciprocal fit. The originality of this study is in the knowledge contribution of the reciprocal fit concept and the integration of resource-based view and reciprocal determination theory as the underpinning theories supporting the concept.
\end{abstract}

Keywords-reciprocal fit, mission statement, reciprocal determination theory, resource-based view

\section{INTRODUCTION}

Researchers agree that the mission statement' effectiveness is not yet established [25]. Some researchers revealed mixed findings in their studies [9], and contradictory [25]. The organizations with more comprehensive mission statements can experience higher performance. Research found evidence supporting this assumption [9]. Other research, however, has shown evidence that does not support such a positive relationship. A study of 59 Times magazine top organizations showed relationship between content of mission statement and organizations' outcomes. A research explored the relationship between organizational outcomes and mission statement orientation of $143 \mathrm{UK}$ public listed companies in both the service and non-service sectors concluded with mixed results [4]. The reciprocal fit approach is based on [5] reciprocal determination theory. However, there is a lack of research into this fit concept and the concept is in needs of further clarification. Thus this study aims to elucidate the concept of reciprocal fit by: 1) investigating the theoretical underpinning of the fit concepts; 2) identifying the conditions of reciprocal fit; and 3) find empirical evidence supporting this reciprocal fit.

\section{THEORETICAL UNDERPINNING}

The RBV concept is concerned with the efficient use of internal resources by companies to gain competitive advantage in the context of changing environments [29]. Superior performance of organizations is determined by how resources are used [7]. According to [13], the 'purpose' of the organization expresses the organization's uniqueness, which should be inspirational. In fact, the mission statement comprises not solely the unique purpose of the organization but its unique vision and values as well [12]. The mission statement captures the uniqueness of the organization and is used for both strategic and cultural alignment. This is consonant with the RBV to the extent that the mission statement as an internal resource can be used for sustainable competitive advantage.

Strategic alignment has been studied under $[1 ; 30]$. Researchers claim that the alignment of human resource practices contributes to sustainable competitive advantage of the firm [1]. Such human resource alignment falls under the purview of RBV. According to [23], the strategic alignment of human resource practices (HRP) offers better explanatory power in terms of aggregating individual-level performance to the firm level.

Furthermore, organizational culture is critical for sustainable competitive advantage if it fulfils the stricture of being rare, valuable, and imitable in RBV [6]. The concept of value congruence is replicated in mission statement research by [24]. A firm that has a strong culture is said to have a 
sustainable competitive advantage over its competitors in the RBV [8]. This concept of value congruence (VC) is indicates the level with which the employees of the firm have similar values as the organisational culture. In mission statement research, VC has been used to represent the cultural element of the firm $[13 ; 16]$.

To extend the understanding of internal capabilities as a source of sustainable competitive advantage [5] reciprocal determination theory (RDT) is used in this study to posit a fit construct which captures this unique capability of the firm. This study proposes that a reciprocal relationship can exist between the strategic and cultural elements which can further strengthen competitive advantage of the firm. According to RDT, "People are neither deterministically controlled by their environments nor entirely self-determining" [11, p. 18]. Bandura stresses that, "in an interactional process, one and the same event can be a stimulus, a response, or an environmental reinforcer..." [5, p. 347]. RDT has been applied in education research. For example, in [26], RDT is used to describe how individuals exposed to learning materials about breastfeeding (environment) affects their perceptions and knowledge (person) which in turns also affects their practices of breastfeeding (behavior). RDT has been applied to the organizational studies by [11] and [20], [21], [23] to explain the reciprocal relationship between safety culture (people) and organizational practices (environment). There is a "triadic reciprocal causation" in RDT [21, p. 118]; namely the internal psychological aspect, the environment, and the behavioral aspect (Refer to Figure 1). [22] application of RDT breaks down each element in them model to posit specifically safety climate as the psychological aspect, safety system as the environment, and job behavior as the behavioral aspect (Figure $1)$.

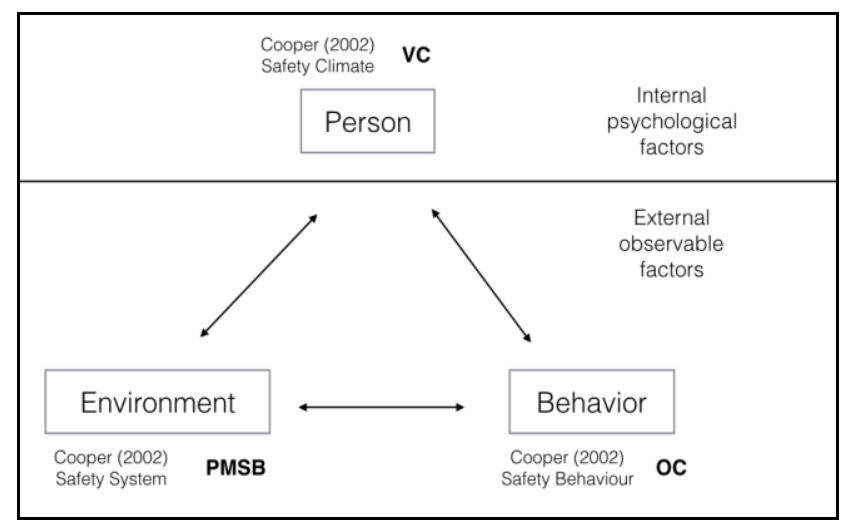

Fig. 1 Bandura's Model of Reciprocal Determination Theory

RDT continues to be a robust theory applied in research. RDT is a suitable framework to understand the reciprocal relationship between VC and HRP. High VC indicates convergence in values between the employees and the organization while a high degree of alignment of HRP with the mission statement indicates consistency in HR policies and practices in attaining the strategic objectives of the firm. In
RDT, VC reflects the personal dimension whereas the HRP reflects the environment in RDT. A reciprocal relationship exists when the relationship between VC and HRP reinforces both. High VC employees will tend to construe HR practices in favourable terms. The HRP will in turn tend to support values and behaviours in line with the culture. This reciprocal relationship has the strongest interaction when both the strategic and cultural elements are aligned with the mission statement. This is detected by a fit construct. Therefore, RDT complements RBV as the combined underpinning theory of this study because the reciprocal relationship can strengthen strategic alignment and organisational culture. This adds further to sustainable competitive advantage.

\section{RECIPROCAL FIT}

Reciprocal fit, F, is founded on the premise of the reciprocal determination theory (RDT) as a source of sustainable competitive advantage using resources within the firm which presupposed the RBV. It is defined as the positive reinforcing relationship between two elements of the firm. As discussed in preceding section, in RDT, a reciprocal relationship exists when the relationship between two elements (in this case, VC and HRP) reinforces both. For example: High $\mathrm{VC}$ employees will tend to construe HR practices in favourable terms. And the HR practices will in turn tend to support values and behaviours in line with the culture thus increasing VC. Conceptually the relationships between two elements of the firm (A and B) can be positive, neutral, or negative. The possible combinations of relationships are illustrated in Table 2.

TABLE 1

THE RELATIONSHIP BETWEEN TWO ELEMENTS A AND B

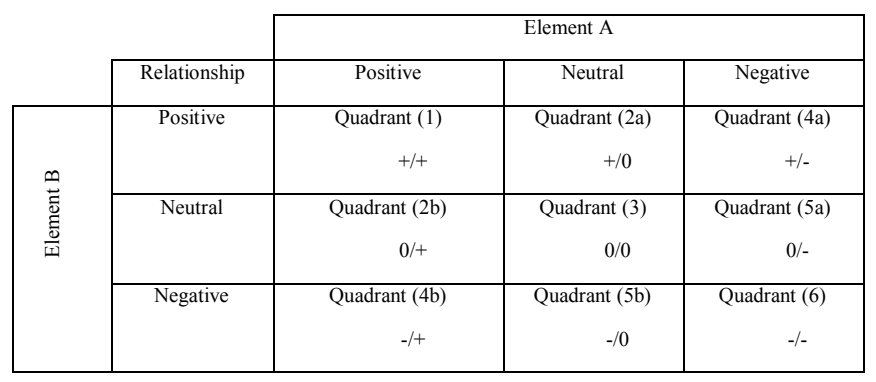

Only in Quadrant (1) does the ideal relationship of a positive reciprocal relationship exist. Quadrants (2a) and (2b) reflect the sub-ideal position where only one element exhibits a positive reinforcing relationship while the other is has a neutral effect. Quadrant (3) reflects the position where both elements exhibit neutral relationships on each other. Quadrants (4a) and (4b) contain conflicting relationships while Quadrant (5a) and (5b) show impeding relationships with one element negative impacting the other while the other having a neutral effect in return. Finally, Quadrant 6 represents the worst scenario where other elements negatively impact each other. Conceptually, Quadrants (1), (2a), (2b), and (3) reflect possible combinations of relationships and only Quadrant (1) qualifies as achieving reciprocal fit, F. It can be seen therefore that the $\mathrm{F}$ as the most 
stringent position and since $\mathrm{F}$ consists of positive reciprocal relationships between the two elements, its effect on the performance of the firm is expected to be greatest.

\section{EVIDENCE OF RECIPROCAL FIT FROM PAST STUDIES}

First, evidence shows HRP influences organizational culture supporting Quadrants (1) and (2a) positions. There is evidence from research that HRP influences the strength of a culture in terms of similarity of behaviours, attitudes, and beliefs. [10] study on the alignment of human resource practices in the not-for profit health care sector - similar to HRP - found that, higher level of internal alignment to the mission statement resulted in higher level of satisfaction with other organizational arrangements. This shows an impact on the behaviours and attitudes of employees. [31] shows different reward systems to result in supporting specific organizational cultures. Because the organizational culture is specific, this suggests similarity of employee behavior, attitudes, and beliefs. Kerr and Slocum found that a hierarchybased rewards system gives rise to a clan culture, whereas a performance-based rewards system gives rise to a market culture. In the clan culture, a complete socialization process ensures employees' behavior and attitudes are congruent towards shared ideals [31]. In a market culture, "there is little pressure from peers to conform to specific behaviours or attitudes [31, p. 135]. Relationships in the market culture are mediated through negotiated contractual agreements between superiors and subordinates based on performance and rewards. This shows that different human resource practices (E.g. rewards systems) can shape behaviours and attitudes reflecting specific types of culture. In this case, specificity in the types of culture means that similarities in values are strengthened. This indicates that HR practices can reinforce specific values and strengthen the culture of the organization. Furthermore, HRP that are not aligned with strategic objectives can negatively impact the strength of the culture [2]. High-tech firms complained of lowered levels of creativity and experimentation when HR policies restricted hiring solely to graduates with engineering degrees [2]. This implies that hiring graduates with other degrees than engineering can improve innovation in high-tech firms. This may also mean that graduates with homogeneous academic backgrounds in engineering tend to have an attitude of risk aversion. This shows that hiring practices have an impact on organizational culture. In [32] case study, CEO's careful attention towards HR practices such as selection, hiring, socializing, and training contributes towards strengthening organizational culture. This effect is corroborated by two studies in hospital settings [3]. [27] indicates that HR practices related to selection, training, and staff socialization are important to maintain a desired organizational culture. This is confirmed by [28]. Their research shows that different HR practices reinforce different types of behaviours, attitudes, and beliefs reflecting a specific culture. There is therefore substantial evidence from research discussed above that HR practices can strengthen organizational culture.
Second, evidence shows organizational culture influences HRP supporting Quadrant (1) and (2b) positions. To put it differently, while the first set of evidence shows that HRP influences organizational culture, this second set of evidence attempts to show that the reverse relationship is also true. This evidence suggests that the strength of the culture affects employee commitment towards the organization in general. [28, p. 58] suggest that organizational culture affects HR practices by claiming that the adoption of HR policies and practices are influence by organizational culture. This relationship has also been confirmed by [32] case study, in which Matsushita's culture was found to shape employee attitudes and acceptance of strategic elements such as the performance management system and the reward system. Despite having stringent selection, training, and development practices, Matsushita's staff accepted and viewed these practices positively. For example, conflicts in Matsushita are viewed as "disagreement between husbands and wives in healthy marriages" [32, p. 48] and investigations and inquisitions by senior managers are viewed by junior managers as appropriate training "to build competence for the day when they [the senior managers] will no longer be around" [32, p. 47]. Such favourable attitudes and acceptance are contrasted by the responses from ITT's staff who faced similarly demanding practices but a different culture. In ITT the culture is one of fear, where meetings become "acid tests" [32, p. 70] to determine whether managers are individually caught "uninformed" by the CEO and "humiliated" in front of his or her peers (p. 71). Performance feedback was viewed as "training" in Matsushita, but are treated as "being picked to death" in ITT. [32] carefully showed that Matsushita and ITT have similar HR practices but different cultures. This shows that in organizations where the culture is strong, it influences the attitude and acceptance of the organization's human resource practices such as HRP. [18] quantitative study of firms in Singapore after mergers and acquisitions, reveals that firms with certain types of organizational culture (together with a 'complementary' human resource system) achieve higher financial performance. This indicates a relationship between certain specific aspects of culture and HR practices, and subsequent impact on performance. They further suggest a fit situation resulting from a 'complementary' relationship. In another study, researchers remarked that there is a reciprocal relationship reinforcing both $\mathrm{HR}$ and organizational culture [19]. Finally, a review study consolidates past research and further confirms the positive role of organizational culture in impacting HR practices [17].

Finally, in [32], this mutual relationship between human resource practices and organizational culture is recorded. [28, p. 58] observed that, "the influence runs both ways." In mission statement research, research by [14, p. 17] supports this mutual influencing relationship by affirming a resonating and reinforcing relationship between the strategy and values of the firm. Therefore, there is sufficient empirical evidence from both past quantitative and qualitative research discussed to support the reciprocal fit concept. 


\section{CONCLUSION}

This study has shown that there is sufficient evidence to establish the case for research on reciprocal relationships in mission statement research. There is a theoretical basis for such reciprocal relationship based on the reciprocal determination theory of [5] supporting the RBV widely assumed in mission statement research. Preceding discussion delineates the reciprocal fit concept. The concept is based on both quantitative and qualitative empirical evidence of reciprocal relationship between VC and HRP. Reciprocal relationships between other aspects of the firm were not discussed which provide ample opportunities for future research. Future studies should also include the reciprocal fit concept to determine mission statement effectiveness. Furthermore, future studies should exploration the possible relationships as identified in Quadrants (3), (4a), (4b), (5a), $(5 b)$, and (6) in Table 2 which are not covered in this study to identify possible factors to ameliorate them to move towards Quadrant (1).

\section{REFERENCES}

1] Amit, R. and Belcourt, M., "Human resources management processes: A value-creating source of competitive advantage", European Management Journal, Vol. 17, No. 2, pp. 174-181, 1999.

[2] Anders, G. (2015). "That "useless" liberal arts degree has become tech's hottest ticket".[Online] available at: http://www.forbes.com/sites/georgeanders/2015/07/29/liberal-artsdegree-tech/\#3295cfc5a754 [Assessed:1 July, 2019].

[3] Anson, B. R., "Taking charge of change in a volatile healthcare marketplace", People and Strategy, Vol. 23, No. 4, p. 21, 2000.

[4] Atrill, P., Omran, M. and Pointon, J., "Company mission statements and financial performance”, Corporate Ownership and Control, Vol. 2 No. 3, pp. 28-35, 2005.

[5] Bandura, A., "The self system in reciprocal determinism", American Psychologist, Vol. 33, No. 4, p. 344, 1978.

[6] Barney, J., "Organizational culture: can it be a source of sustained competitive advantage?", Academy of Management Review, Vol. 11, No. 3, pp. 22-23, 1986.

[7] Barney, J. "Firm resources and sustained competitive advantage", Journal of Management, Vol. 17, No. 1, pp. 99-120,1991.

[8] Barney, J. B. and Clark, D. N. Resource-based theory: Creating and sustaining competitive advantage. Oxford University Press on Demand, Oxford, 2007.

[9] Bart, C. and Baetz, M. C., "The relationship between mission statements and firm performance: An exploratory study", Journal of Management Studies, Vol. 3, No. 6, pp. 823-853,1998.

[10] Bart, C. and Tabone, J. J. C., "Mission statement rationales and organizational alignment in the not-for-profit health care sector", Health Care Management Review, Vol. 23, No. 4, pp. 54-69, 1998.

[11] Blair, E., "Culture and leadership", Professional Safety, Vol. 48, No. 6, p. $18,2003$.

[12] Braun, S., Wesche, J., Frey, D. and Weisweiler, S., "Effectiveness of mission statements in organizations: A review", Journal of Management and Organization, Vol. 18, No. 4, pp. 430-444, 2012.

[13] Campbell, A., "The power of missions: Aligning strategy and culture", Planning Review, Vol. 20, No. 5, pp. 10-63, 1992.
[14] Campbell, A., Mission and Management Commitment. Ashridge strategic management cenre, London, 1996.

[15] Campbell, A. and Nash, L. L., A sense of mission: Defining direction for the large corporation, Addisen-Wesley Longman, Massachusetts,1992.

[16] Campbell, A. and Yeung, S., "Creating a sense of mission", Long Range Planning, Vol. 24, No. 4, pp. 10-20,1991.

[17] Carroll, W., Dye, K. and Wagar, T. Role of organizational culture in strategic human resource management. In N. M. Ashkanasy, C. P. M. Wilderom, and M. F. Peterson Eds., The Handbook of Organizational Culture and Climate, 2011, pp. 423-440.

[18] Chew, I. K. H. and Sharma, B., "The effects of culture and HRM practices on firm performance - Empirical evidence from Singapore", International Journal of Manpower, Vol. 26, No. 6, pp. 560-581, 2005.

[19] Chow, I. H.-S. and Shan, S. L., "Business strategy, organizational culture, and performance outcomes in China's technology industry", People and Strategy, Vol. 30, No. 2, p. 47, 2007.

[20] Cooper, D., Improving safety culture: A practical guide, John Wiley \& Sons, New Jersey, 1988.

[21] Cooper, D., "Towards a model of safety culture", Safety Science, Vol. 36, No. 2, pp. 111-136, 2000.

[22] Cooper, D. "Safety culture", Professional Safety, Vol. 47, No. 6, p. 30, 2002.

[23] DeNisi, A. and Smith, C. E., "Performance appraisal, performance management, and firm-level performance: a review, a proposed model, and new directions for future research", The Academy of Management Annals, Vol. 8, No. 1, pp. 127-179, 2014.

[24] Desmidt, S. and Heene, A., Mission statements: In search for ameliorated performance through organisation-employee value congruence, In The First workshop of the EGPA Study Group on Ethics and Integrity of Governance, 2003.

[25] Desmidt, S., Prinzie, A. and Decramer, A., "Looking for the value of mission statements: A meta-analysis of 20 years of research", Management Decision, Vol. 49, No. 3, pp. 68-483, 2011.

[26] Devi, B., Khandelwal, B. and Das, M., “Application of Bandura's social cognitive theory in the technology enhanced, blended learning environment", International Journal of Applied Research, Vol. 3, No. 1, pp. 721-724, 2017.

[27] Guest, D. E., "Organizational psychology and human resource management: Towards a European approach", European Journal of Work and Organizational Psychology, Vol. 4, No. 3, pp. 251-270, 1994.

[28] Hartog, D. N. D. and Verburg, R. M., "High performance work systems, organisational culture and firm effectiveness", Human Resource Management Journal, Vol. 14, No. 1, pp. 55-78, 2004.

[29] Hoopes, D. G., Madsen, T. L. and Walker, G., "Why is there a resourcebased view? Toward a theory of competitive heterogeneity" Strategic Management Journal, Vol. 24, No. 10 SPEC ISS., pp. 889-902, 2003.

[30] Hung, R. Y.-Y., "Business process management as competitive advantage: A review and empirical study", Total Quality Management and Business Excellence, Vol. 17, No. 1, pp. 21-40, 2006.

[31] Kerr, J. and Slocum, J., "Managing corporate culture through reward systems", The Academy of Management Executive, Vol. 19, No. 4, pp. 130-138, 1987.

[32] Pascale, R. and Athos, A., Art of Japanese management, Penguin Books, London, 1982. 